Journal of Advanced Research in Fluid Mechanics and Thermal Sciences

\title{
Water Infiltration into Sand, Silt, and Clay at Field Capacity
}

\author{
Goh Eng Giap ${ }^{1,2,}{ }^{*}$, Rudiyanto ${ }^{3}$, Mohd Sofiyan Sulaiman ${ }^{1,2}$ \\ Faculty of Ocean Engineering Technology and Informatics, Universiti Malaysia Terengganu, 21030 Kuala Nerus, Terengganu, Malaysia \\ Hydrology and Water Resources Research Interest Group, Universiti Malaysia Terengganu, 21030 Kuala Nerus, Terengganu, Malaysia \\ Program of Crop Science, Faculty of Fisheries and Food Science, Universiti Malaysia Terengganu, 21030 Kuala Nerus, Terengganu, Malaysia
}

\section{ARTICLE INFO ABSTRACT}

\section{Article history:}

Received 11 April 2021

Received in revised form 1 July 2021

Accepted 2 July 2021

Available online 24 July 2021

Keywords:

Water flux; water movement; crop water demand; soil moisture content
Field capacity (FC), permanent wilting (PWP), and plant available water (PAW) are essential parameters to estimate for soils because they are essential for water irrigation management. However, these parameters were reported in water volume per unit soil volume. Knowing the soil required water volume does not imply immediate water availability, that is, the speed at which the water could be supplied to the soil. This is because there is a lag time between water irrigation initiation and the water increment in the soil depth. This study uses the field capacity's soil water content to simulate the water infiltration using Richards' equation. The studied soil medium was silt, sand, and clay. The study allows an estimate of water infiltration time and infiltrated water to relate to the soil depth of interest. The clayey has the highest FC, and the silty soil has the highest PAW. The results revealed silty soil could contain more readily water for plant growth than sand and clay. This study also revealed silty soil to be a better soil medium than sand and clay. It has the best trade-off between water infiltration time and the infiltrated amount of water for plant absorption. This study's coupling technique will be a useful tool for farmers and field practitioners to assess any site based on the soil texture at an early stage of water irrigation investigation.

\section{Introduction}

Soil water is an essential element in crop management [1-3]. Under natural conditions, water supplies through rainfall [4], water flux from deeper soil water like groundwater [5], incoming water flux from neighboring soil at higher soil water content [6], and fog and dew formation on the soil surface [7-10]. Human interventions such as cloud seeding [11-13] and water irrigation system [14] would supply water for plants' needs. When the supplied water hits the ground, it seeps into the soil by the gravitational pull [15]. Also, there are attractive forces between water molecules and soil particles, which results in water mass diffusion. These mechanisms resulted in water variability in space and time in subsurface soil.

A way of reporting quantified water in the soil is in soil water content [16]. Soil water content quantifies the water volume in a unit volume of soil [17]. When the pore spaces between soil particles

\footnotetext{
* Corresponding author.

E-mail address: sunnygoh@gmail.com
}

https://doi.org/10.37934/arfmts.84.2.159166 
fill with water, the water stage is known as saturated soil water content [18]. When sufficiently drained by the gravitational pull, the saturated soil water content would result in a soil water content level known as field capacity (FC) [19]. FC is the level at which water remains relatively stagnant in the soil [20-21]. The soil water content is susceptible to further reduction by plant roots absorption [22] and water loss by evaporation [23] at this level. The subsequent decrease in soil water content would reach a permanent wilting point (PWP). The PWP is at a soil water content level that the water molecules are firmly attached to the soil particles [24]. The forces between water molecules and soil particles are far greater than absorption forces by the plant roots. Hence, at the PWP's soil moisture level, the plants begin to wilt due to the plant roots' failure to absorb water. The primary purpose of water irrigation is to achieve soil moisture content within the range of FC and PWP. The difference between FC and PWP is known as PAW [8].

The natural way to achieve the PAW's soil water content range is by rainfall [25]. Alternatively, a soil moisture sensor installed at a soil depth could measure soil water content and indicating the need for water irrigation when it falls below the PWP's soil water content level [27]. This method is appropriate given that the existing water irrigation system and the availability of water resources in the immediate surrounding area can supply the water demand. However, such a condition is relatively too late should the existing system fail to meet the plantation water demand. Hence, earlystage water irrigation planning before plantation begins is necessary.

The PAW indicates the necessity of maintaining the minimum water volume in a soil volume unit to sustain plant water needs. However, it does not indicate the rate of water supply. Water supply rate is essential information for planning the crop water requirement because supplying a water volume in a second, a minute, or an hour has a significant implication on the water irrigation system and storage design. Thus, the current study addresses the knowledge gap using the Richards' equation to estimate the water infiltration rate into the soil at field capacity's soil moisture content. The study develops the reference data to relate soil depth, water infiltration time, and water infiltration rate. The information can be useful to farmers or field practitioners as a screening tool for an early-stage site water demand assessment.

\section{Methodology}

Sandy, silty, and clayey soils were used in the current study. Rosetta [28] was used to generate the van Genuchten equation's parameters [29], and the parameters were used in the characteristic function. The characteristic curve (Eq. (1)) and the unsaturated hydraulic conductivity-water content (Eq. (2)) for van Genuchten equations used to represent the soil, respectively, were,

$$
\begin{aligned}
& \theta_{L}\left(\psi_{m}\right)=\theta_{r}+\frac{\theta_{s}-\theta_{r}}{\left[1+\left(\alpha \psi_{m}\right)^{n}\right]^{1-1 / n}} \\
& K\left(\theta_{L}\right)=K_{s}\left(\frac{\theta_{L}-\theta_{r}}{\theta_{s}-\theta_{r}}\right)^{L}\left\{1-\left[1-\left(\frac{\theta_{L}-\theta_{r}}{\theta_{s}-\theta_{r}}\right)^{1 / m}\right]^{m}\right\}^{2}
\end{aligned}
$$

The field capacity (FC) and permanent wilting point (PWP) were estimated using Eq. (1). The soil matric suction used to estimate soil water content at FC and PWP were -3.3 and $-150 \mathrm{~m}$, respectively [30]. The FC and PWP were estimated for sand, silt, and clay. 
Richards' equation [31] simulates water infiltration into unsaturated soil. The equation was used in the current study, as below [32]:

$$
\frac{\partial \theta_{L}}{\partial t}=\frac{\partial}{\partial z}\left[K\left(\frac{\partial \psi_{m}}{\partial \theta_{L}}\right) \frac{\partial \theta_{L}}{\partial z}-K\right]
$$

Eq. (3) is a mass balance equation in which the right side of the equation governs the mass flux of water enters and leaves the soil volume in space, and the left side of the equation governs the accumulation as in mass appreciation or depreciation with time. Other than diffusion and gravity mechanisms given in Eq. (3), heat could also influence the flow of water in porous media, but not consider in the current study [33]. In some situations, multiphase flows in porous media are also possible [34].

Richards' equation can be solved using finite difference solution, and the solution in the algebra form is as follows [35]:

$$
\begin{aligned}
& \frac{\theta_{L(k)}{ }^{n+1}-\theta_{L(k)}{ }^{n}}{\Delta t}=\frac{K_{k+1 / 2}\left(\partial \psi_{m} / \partial \theta_{L}\right)_{k+1 / 2}\left(\theta_{L(k+1)}{ }^{n+1}-\theta_{L(k)}{ }^{n+1}\right)}{(\Delta z)^{2}} \\
& -\frac{K_{k-1 / 2}\left(\partial \psi_{m} / \partial \theta_{L}\right)_{k-1 / 2}\left(\theta_{L(k)}{ }^{n+1}-\theta_{L(k-1)}{ }^{n+1}\right)}{(\Delta z)^{2}}-\frac{K_{k+1 / 2} \vec{k}-K_{k-1 / 2} \vec{k}}{\Delta z}
\end{aligned}
$$

A thorough explanation of the numerical scheme used is available in Goh and Noborio [36].

\section{Results and Discussion}

Figure 1 shows the relation of soil water content with soil matric suction from 0 to $-10,000,000$ $\mathrm{cm}$ negative pressure head for clayey soil. When there is zero matric suction (or zero pressure head), the clayey soil is at a fully saturated state in which the water has filled the entire pore spaces between the soil particles. The fully saturated water content for clayey soil has a value of $0.459 \mathrm{~m}^{3} \cdot \mathrm{m}^{-3}$. When the soil matric suction begins to rise, that is, at the increasing suction pressure head, the soil water begins to drain [16]. Initially, the water drains at a low rate, but as the suction pressure keeps increasing, a sudden increase in the water loss rate occurred. Continue increasing the suction pressure would eventually result in a plateau state in the soil water content region. The plateau soil water content is known as residual soil water content with a value of $0.098 \mathrm{~m}^{3} \cdot \mathrm{m}^{-3}$. In a similar trend, the saturated and residual water contents for sandy soil correspond to 0.375 and $0.053 \mathrm{~m}^{3} \cdot \mathrm{m}^{-3}$, while the silty soil has 0.489 and $0.050 \mathrm{~m}^{3} \cdot \mathrm{m}^{-3}$, respectively.

The van Genuchten equation in Eq. (1) represents the curvature in Figure 1 for clay. Eq. (1) represents the relation between soil water content and soil matric suction. The field capacity's soil moisture content for clayey soil was predicted using the $-3.3 \mathrm{~m}$ soil matric suction as input in Eq. (1). Similarly, the permanent wilting point for clayey soil was determined at $-150 \mathrm{~m}$ soil matric suction using Eq. (1). The same procedure was emulated for sand and silt. The field capacity (FC) and permanent wilting point (PWP) results are shown in Table 1. The FC's soil water content was determined because it indicates the amount of water lower than this limit would remain relatively constant in the soil, except being absorbed by the plant's roots or dry by evaporation. The PWP's soil water content indicates the maximum level at which plant roots could absorb the soil water content; 
lower than the PWP's soil water content, the water would firmly attach to the soil greater than plant root absorbing pressure.

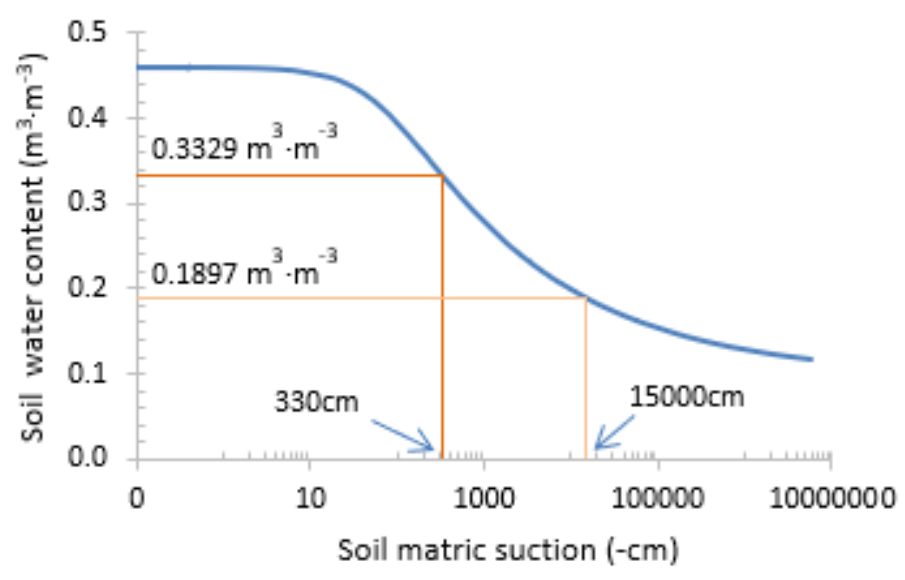

Fig. 1. The characteristic curve for clayey soil texture. The field capacity's soil water content was found as 0.3329 $\mathrm{m}^{3} \cdot \mathrm{m}^{-3}$ at soil matric suction of $-330 \mathrm{~cm}$ *Similarly, the permanent wilting point at $0.1897 \mathrm{~m}^{3} \cdot \mathrm{m}^{-3}$ soil moisture content was determined at $-15000 \mathrm{~cm}$ soil matric suction

Table 1 shows the FC and PWP for silt, clay, and sand. The FC's soil water content decreased in the order as $\mathrm{FC}_{\text {clay }}>\mathrm{FC}_{\text {silt }}>\mathrm{FC}_{\text {sand, }}$, while the PWP's soil water content was similar in the decreasing order as $\mathrm{PWP}_{\text {clay }}>\mathrm{PWP}_{\text {silt }}>\mathrm{PWP}_{\text {sand. }}$. However, the plant available water (PAW), estimated by PAW = FC - PWP [37], was found in the following order $\mathrm{PAW}_{\text {silt }}>\mathrm{PAW}_{\text {clay }}>\mathrm{PAW}_{\text {sand. }}$. Thus, clay has the highest water storage (FC) compared to silt and sand; the highest in PWP for clayey soil than silt and sand has reduced its ability to provide readily available water (PAW) for plant root absorption. For this reason, silt has overtaken clay as a soil texture that provides the most readily available water for plant root absorption.

\section{Table 1}

Field capacity (FC), permanent wilting point (PWP), and plant available water (PAW) for sand, silt, and clay

\begin{tabular}{llll}
\hline Soil texture & $\mathrm{FC}\left(\mathrm{m}^{3} \cdot \mathrm{m}^{-3}\right)$ & $\mathrm{PWP}\left(\mathrm{m}^{3} \cdot \mathrm{m}^{-3}\right)$ & $\mathrm{PAW}\left(\mathrm{m}^{3} \cdot \mathrm{m}^{-3}\right)$ \\
\hline Clay & 0.333 & 0.190 & 0.143 \\
Sand & 0.055 & 0.053 & 0.002 \\
Silt & 0.285 & 0.069 & 0.216 \\
\hline
\end{tabular}

* The field capacity and permanent wilting point soil moisture contents were determined at -3.3 and $-150 \mathrm{~m}$, respectively. The negative sign indicates negative pressure or soil particles suction (attraction) pressure. The equation FC - PWP soil water contents give the estimate for PAW

The PAW is a good indication of soil water content must be present in the soil necessary to maintain readily available water for plant growth. However, it does not indicate the rate at which soil water must be supplied into the soil or the rate of water infiltration into the soil by an irrigation system to sustain the determined PAW. For this reason, Richards' equation was used to estimate the water infiltration [36-39] into the soil at field capacity. Figure 2 shows the water infiltration profile into the clayey soil at different times. The observation was similar to those observed in Goh and Noborio [42]. Until 0.12 days of water infiltration, the entire soil depth remained relatively dry. At 
231.48 days, the water has infiltrated into $0.6 \mathrm{~m}$ depth of soil. The longer the time allowed for water infiltration, the deeper the water infiltrates into the soil. There was a lag time between the initiation of water infiltration and soil water content rise at a deeper soil depth [27]. A similar observation was also observed for silty and sandy soils.

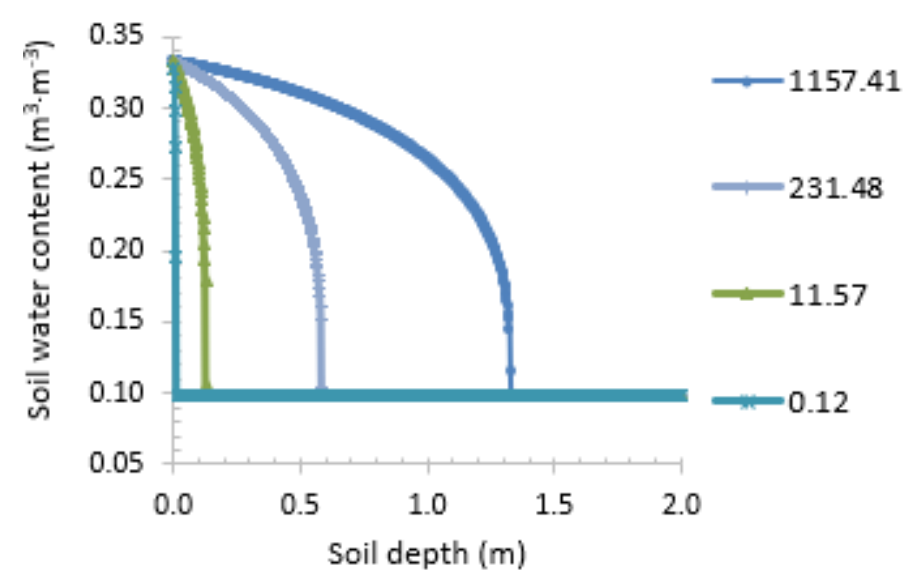

Fig. 2. The variation of soil water contents with soil depths. The curves indicate water infiltration front at $0.12,11.57,231.48$, and 1157.41 days

Figure 3(a) and 3(b) show the relation between soil depth of interest with the water infiltration time and the infiltrated water. The infiltrated water was referring to the depth of water that has infiltrated into the soil. Different plant roots have different lengths. For example, onions, radish, and spinach were collectively roots depth of $0.15 \mathrm{~m}$, whereas $0.3 \mathrm{~m}$ for celery, shallots, swiss chard, and $0.45 \mathrm{~m}$ for broccoli, cabbage, carrots, cauliflower, cucumbers, eggplants, kale [43]. Hence, different soil depths were selected in this study. Figure 3(a) showed the time for water to infiltrate into silty soil at $0.15 \mathrm{~m}$ depth was 6.1 times more than the time required for sand, whereas only 0.4 times that was faster than the clay. At $0.3 \mathrm{~m}$ depth, silty soil was found to have 5.2 times that of sandy soil and again 0.4 times that of clayey soil. A similar trend was observed for $0.45 \mathrm{~m}$ depth.

Figure 3(b) showed the silty soil has 334.1 times greater amount of water infiltrated into the soil than sand, while only 0.9 times when compared to clay. In water irrigation management, it is desirable to irrigate the soil and supply the water to the desired depth within the short time possible, that is, the minimum time lag between irrigation initiation and water increment at the desired soil depth. Sandy soil seemed to have met this requirement with the most minimum time required to irrigate the desire soil depth, but the amount of water it could contain was 0.003 times that of silt and clay for all depths. Hence, silt appeared in a better tradeoff in water infiltration time and infiltrated water than sand and clay. 


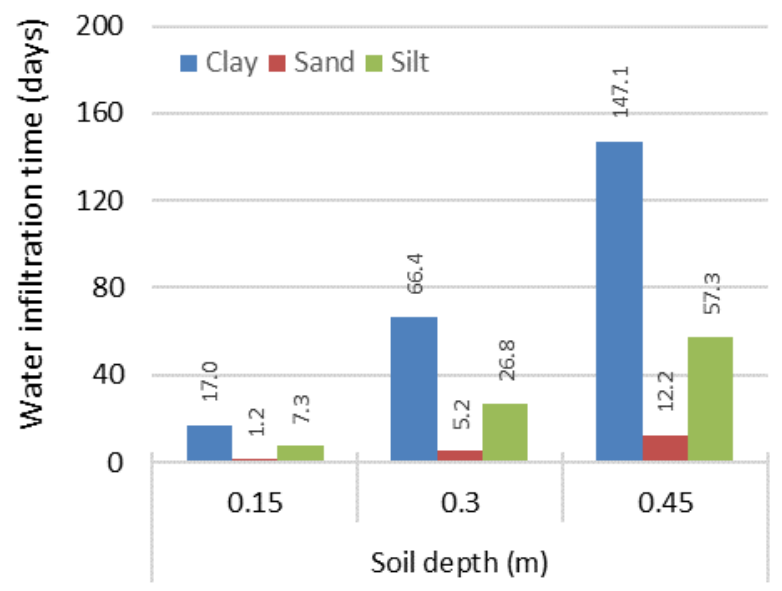

(a)

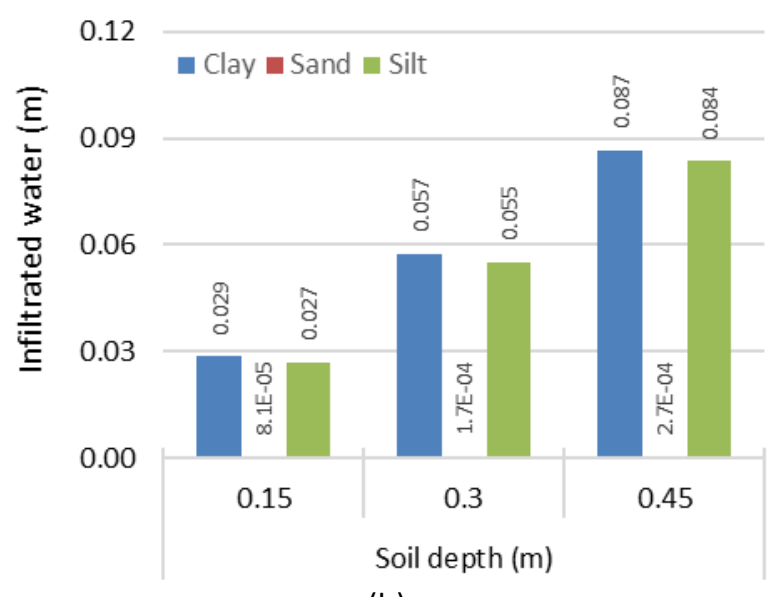

(b)

Fig. 3. (a) Water infiltration time to different soil depths, and (b) infiltrated water $\left(\mathrm{m}^{3}\right.$ water in $\mathrm{m}^{2}$ land area) to different soil depths. The soil depths were $0.15,0.3$, and $0.45 \mathrm{~m}$, and the soil textures were sand, clay, and silt

\section{Conclusions}

Field capacity (FC), permanent wilting (PWP), and plant available water (PAW) are essential parameters in water irrigation management. The FC was found greater in clay than silt and sand. A similar observation was found in PWP. However, silt was found to have the greatest PAW compared to sand and clay. PAW is an essential parameter to indicate water volume must be supplied to the soil depth, but it does not indicate the speed at which water rises in the soil pore space. The Richards' equation coupled with the field capacity value for water infiltration was used to solve this limitation. The results showed that sand has the shortest infiltration time compared to silt and clay. Similarly, sand also has the lowest amount of water infiltrated into the soil. Since the best choice was to have the shortest infiltration time and considerable water amount infiltration into the soil at field capacity, silt soil in the current study turnout to be the best among the three soils. This study revealed the usefulness of coupling Richards' equation and field capacity's soil moisture content. The results will be useful for farmers and field practitioners as early site assessment on crop water management.

\section{Acknowledgment}

We would like to acknowledge the financial support from the Ministry of Higher Education Malaysia (FRGS/1/2020/STG08/UMT/02/2) (VOT UMT 59611).

\section{References}

[1] Green, Timothy R., and Robert H. Erskine. "Measurement, scaling, and topographic analyses of spatial crop yield and soil water content." Hydrological Processes 18, no. 8 (2004): 1447-1465. https://doi.org/10.1002/hyp.1422

[2] Novara, Agata, Artemi Cerda, Ettore Barone, and Luciano Gristina. "Cover crop management and water conservation in vineyard and olive orchards." Soil and Tillage Research 208 (2021): 104896. https://doi.org/10.1016/j.still.2020.104896

[3] Yang, Wei, Gary Feng, John J. Read, Ying Ouyang, Jianjun Han, and Pinfang Li. "Impact of cover crop on cornsoybean productivity and soil water dynamics under different seasonal rainfall patterns." Agronomy Journal 112, no. 2 (2020): 1201-1215. https://doi.org/10.1002/agi2.20110

[4] Han, Tongchun, Liqiao Liu, and Gen Li. "The influence of horizontal variability of hydraulic conductivity on slope stability under heavy rainfall." Water 12, no. 9 (2020): 2567. https://doi.org/10.3390/w12092567

[5] Morales Santos, Angela, and Reinhard Nolz. "Assessing canopy temperature-based water stress indices for soybeans under subhumid conditions." In EGU General Assembly Conference Abstracts, p. 16325. 2020. https://doi.org/10.5194/egusphere-egu2020-16325 
[6] Bandai, Toshiyuki, and Teamrat A. Ghezzehei. "Physics-informed neural networks with monotonicity constraints for Richardson-Richards equation: Estimation of constitutive relationships and soil water flux density from volumetric water content measurements." Water Resources Research 57, no. 2 (2021): e2020WR027642. https://doi.org/10.1029/2020WR027642

[7] Yu, Ruihong, Zhuangzhuang Zhang, Xixi Lu, I-Shin Chang, and Tingxi Liu. "Variations in dew moisture regimes in desert ecosystems and their influencing factors." Wiley Interdisciplinary Reviews: Water 7, no. 6 (2020): e1482. https://doi.org/10.1002/wat2.1482

[8] Kidron, Giora J., and Rafael Kronenfeld. "Assessing the likelihood of the soil surface to condense vapour: The Negev experience." Ecohydrology 13, no. 3 (2020): e2200. https://doi.org/10.1002/eco.2200

[9] Feigenwinter, Christian, Joel Franceschi, Jarl Are Larsen, Robert Spirig, and Roland Vogt. "On the performance of microlysimeters to measure non-rainfall water input in a hyper-arid environment with focus on fog contribution." Journal of Arid Environments 182 (2020): 104260. https://doi.org/10.1016/i.jaridenv.2020.104260

[10] Adhikari, Bishwodeep, and Lixin Wang. "The potential contribution of soil moisture to fog formation in the Namib Desert." Journal of Hydrology 591 (2020): 125326. https://doi.org/10.1016/i.jhydrol.2020.125326

[11] Alsharhan, Abdulrahman S., and Zeinelabidin E. Rizk. "Water harvesting." In Water resources and integrated management of the United Arab Emirates, pp. 609-630. Springer, Cham, 2020. https://doi.org/10.1007/978-3-03031684-6 20

[12] Zahraie, Banafsheh, Hamed Poursepahy Samian, Mohsen Nasseri, and S. Mahmood Taheri. "Statistical Evaluation of Cloud Seeding Operations in Central Plateau of Iran in the 2015 Water Year." Journal of the Earth and Space Physics 47, no. 1 (2021): 187-203. https://dx.doi.org/10.22059/jesphys.2021.312050.1007255

[13] Patle, G. T., Mukesh Kumar, and Manoj Khanna. "Climate-smart water technologies for sustainable agriculture: A review." Journal of Water and Climate Change 11, no. 4 (2020): 1455-1466. https://doi.org/10.2166/wcc.2019.257

[14] Allen, L. Niel, and Jennifer W. MacAdam. "Irrigation and water management." Forages: The Science of Grass/and Agriculture 2 (2020): 497-513. https://doi.org/10.1002/9781119436669.ch27

[15] Fuentes, Sebastián, Josué Trejo-Alonso, Antonio Quevedo, Carlos Fuentes, and Carlos Chávez. "Modeling Soil Water Redistribution under Gravity Irrigation with the Richards Equation." Mathematics 8, no. 9 (2020): 1581. https://doi.org/10.3390/math8091581

[16] Jury, William A., and Robert Horton. Soil physics. John Wiley \& Sons, 2004.

[17] Rawls, Walter J., Donald L. Brakensiek, and K. E. Saxtonn. "Estimation of soil water properties." Transactions of the ASAE 25, no. 5 (1982): 1316-1320. https://doi.org/10.13031/2013.33720

[18] Hillel, Daniel. Environmental soil physics: Fundamentals, applications, and environmental considerations. Elsevier, 1998.

[19] Vaheddoost, Babak, Yiqing Guan, and Babak Mohammadi. "Application of hybrid ANN-whale optimization model in evaluation of the field capacity and the permanent wilting point of the soils." Environmental Science and Pollution Research 27, no. 12 (2020): 13131-13141. https://doi.org/10.1007/s11356-020-07868-4

[20] Twarakavi, Navin KC, Masaru Sakai, and Jirka Šimůnek. "An objective analysis of the dynamic nature of field capacity." Water Resources Research 45, no. 10 (2009). https://doi.org/10.1029/2009WR007944

[21] Colman, E. A. "A laboratory procdure for determining the field capacity of soils." Soil Science 63, no. 4 (1947): $277-$ 284. https://doi.org/10.1097/00010694-194704000-00003

[22] Wu, Jinquan, Renduo Zhang, and Shengxiang Gui. "Modeling soil water movement with water uptake by roots." Plant and soil 215, no. 1 (1999): 7-17. https://doi.org/10.1023/A:1004702807951

[23] Hsieh, Jean CC, Oliver A. Chadwick, Eugene F. Kelly, and Samuel M. Savin. "Oxygen isotopic composition of soil water: quantifying evaporation and transpiration." Geoderma 82, no. 1-3 (1998): $269-293$. https://doi.org/10.1016/S0016-7061(97)00105-5

[24] Wiecheteck, Lucia H., Neyde FB Giarola, Renato P. de Lima, Cassio A. Tormena, Lorena C. Torres, and Ariane L. de Paula. "Comparing the classical permanent wilting point concept of soil (-15,000 hPa) to biological wilting of wheat and barley plants under contrasting soil textures." Agricultural Water Management 230 (2020): 105965. https://doi.org/10.1016/i.agwat.2019.105965

[25] Saha, Abhisekh, Bharat Rattan, Sreedeep Sekharan, and Uttam Manna. "Quantifying the interactive effect of water absorbing polymer (WAP)-soil texture on plant available water content and irrigation frequency." Geoderma 368 (2020): 114310. https://doi.org/10.1016/i.geoderma.2020.114310

[26] Zeitoun, Reem, Mark Vandergeest, Hiteshkumar Bhogilal Vasava, Pedro Vitor Ferrari Machado, Sean Jordan, Gary Parkin, Claudia Wagner-Riddle, and Asim Biswas. "In-Situ Estimation of Soil Water Retention Curve in Silt Loam and Loamy Sand Soils at Different Soil Depths." Sensors 21, no. 2 (2021): 447. https://doi.org/10.3390/s21020447

[27] Kassaye, Kassu Tadesse, Julien Boulange, Hirotaka Saito, and Hirozumi Watanabe. "Monitoring soil water content for decision supporting in agricultural water management based on critical threshold values adopted for Andosol 
in the temperate monsoon climate." Agricultural Water Management 229 (2020): 105930. https://doi.org/10.1016/j.agwat.2019.105930

[28] Schaap, Marcel G., Feike J. Leij, and Martinus Th Van Genuchten. "Rosetta: A computer program for estimating soil hydraulic parameters with hierarchical pedotransfer functions." Journal of hydrology 251, no. 3-4 (2001): $163-176$. https://doi.org/10.1016/S0022-1694(01)00466-8

[29] Van Genuchten MT. " A closed-form equation for predicting the hydraulic conductivity of unsaturated soils." Soil Science Society of America Journal 44, no. 5 (1980): $892-898$. https://doi.org/10.2136/sssaj1980.03615995004400050002x

[30] Mohseni, Amir, Hossein Mirseyed Hosseini, and Fariborz Abbasi. "Evaluation of furrow fertigation on nitrogen supply and losses as a function of maize growth stages." SN Applied Sciences 3, no. 1 (2021): 1-9. https://doi.org/10.1007/s42452-020-03998-z

[31] Richards, Lorenzo Adolph. "Capillary conduction of liquids through porous mediums." Physics 1, no. 5 (1931): 318333. https://doi.org/10.1063/1.1745010

[32] Kirkland, Michael R., R. G. Hills, and P. J. Wierenga. "Algorithms for solving Richards' equation for variably saturated soils." Water Resources Research 28, no. 8 (1992): 2049-2058. https://doi.org/10.1029/92WR00802

[33] Ewis, Karem Mahmoud. "Effects of Variable Thermal Conductivity and Grashof Number on Non-Darcian Natural Convection Flow of Viscoelastic Fluids with Non Linear Radiation and Dissipations." Journal of Advanced Research in Applied Sciences and Engineering Technology 22, no. 1 (2021): 69-80. https://doi.org/10.37934/araset.22.1.6980

[34] Duo-Xing, Yang, and Zhang De-liang. "Simulating Multiphase Flows in Porous Media with High Order CE/SE Method." CFD Letters 3, no. 1 (2011): 1-17.

[35] Giap, Goh Eng, and Noborio Kosuke. "Sensitivity analysis using sobol 'variance-based method on the haverkamp constitutive functions implemented in richards' water flow equation." Malaysian Journal of Soil Science 18 (2014): 19-33.

[36] Goh, Eng Giap, and Kosuke Noborio. "Sensitivity analysis and validation for numerical simulation of water infiltration into unsaturated soil." International scholarly research notices 2015 (2015). https://doi.org/10.1155/2015/824721

[37] Koupai, Jahangir Abedi, Seyed Saeid Eslamian, and Jafar Asad Kazemi. "Enhancing the available water content in unsaturated soil zone using hydrogel, to improve plant growth indices." Ecohydrology \& Hydrobiology 8, no. 1 (2008): 67-75. https://doi.org/10.2478/v10104-009-0005-0

[38] Swartzendruber, Dale. "A quasi-solution of Richards' Equation for the downward infiltration of water into soil." Water Resources Research 23, no. 5 (1987): 809-817. https://doi.org/10.1029/WR023i005p00809

[39] Ross, Po Jo. "Efficient numerical methods for infiltration using Richards' equation." Water Resources Research 26, no. 2 (1990): 279-290. https://doi.org/10.1029/WR026i002p00279

[40] Hayek, Mohamed. "Analytical solution to transient Richards' equation with realistic water profiles for vertical infiltration and parameter estimation." Water Resources Research 52, no. 6 (2016): 4438-4457. https://doi.org/10.1002/2015WR018533

[41] Parlange, J-Y., W. L. Hogarth, David Andrew Barry, M. B. Parlange, R. Haverkamp, P. J. Ross, T. S. Steenhuis, D. A. DiCarlo, and G. Katul. "Analytical approximation to the solutions of Richards' equation with applications to infiltration, ponding, and time compression approximation." Advances in Water Resources 23, no. 2 (1999): 189194. https://doi.org/10.1016/S0309-1708(99)00022-6

[42] Goh, E. G., and K. Noborio. "Sensitivity analysis on the infiltration of water into unsaturated soil." In Proceedings of Soil Moisture Workshop, Hiroshima University Tokyo Office in Campus Innovation Center, pp. 66-68. 2013.

[43] NRCS, "New Jersey Irrigation Guide," United States Department of Agriculture Natural Resources Conservation Service Somerset, New Jersey, $2005 . \quad$ Online]. Available: https://www.nrcs.usda.gov/wps/portal/nrcs/detail/nj/technical/engineering/?cid=nrcs141p2 018736 